\title{
Correction to: Fluid handling and blood flow patterns in neonatal respiratory distress syndrome versus transient tachypnea: a pilot study
}

Rana Ismail ${ }^{1}$, Prashanth Murthy ${ }^{1}$, Ayman Abou Mehrem ${ }^{1}$, Zhiying Liang ${ }^{2}$ and Amelie Stritzke ${ }^{2^{*}}$

Correction to: BMC Pediatr 21, 541 (2021)

https://doi.org/10.1186/s12887-021-03025-z

Following the publication of the original article [1], it has been noticed that the author names have been captured incorrectly. The given and family names were interchanged. The correct names are provided in the authorgroup section above and the reference entry below.

The original article has been corrected.

\section{Author details}

${ }^{1}$ Section of Neonatology, Department of Pediatrics, Alberta Health Services, University of Calgary, Cumming School of Medicine, Calgary, Canada. ${ }^{2}$ University of Calgary, Cumming School of Medicine, Libin Cardiovascular Institute of Alberta, Calgary, Canada.

Published online: 19 January 2022

\section{Reference}

1. Ismail R, Murthy P, Abou Mehrem A, et al. Fluid handling and blood

flow patterns in neonatal respiratory distress syndrome versus transient tachypnea: a pilot study. BMC Pediatr. 2021;21:541. https://doi.org/10.

1186/s12887-021-03025-z. 